\title{
EM BUSCA DO DESENVOLVIMENTO REGIONAL: OS INTELECTUAIS E SUAS PROPOSTAS PARA O NORTE DE MINAS GERAIS
}

\section{IN SEARCH OF REGIONAL DEVELOPMENT: INTELLECTUALS AND THEIR PROPOSALS TO THE NORTH OF MINAS GERAIS}

\author{
Ilva Ruas Abreu \\ Universidade Estadual de Montes Claros - Montes Claros - MG - Brasil \\ Laurindo Mekie Pereira \\ Universidade Estadual de Montes Claros - Montes Claros - MG - Brasil \\ Edi de Freitas Cardoso Junior \\ Instituto Federal do Norte de Minas Gerais - Araçuaí - MG - Brasil
}

\begin{abstract}
Resumo: Este artigo apresenta um estudo acerca das ideias e ações de três intelectuais atuantes no norte de Minas Gerais, na segunda metade do século $X X$, no contexto de sua modernização econômica: o empresário Luiz de Paula Ferreira, o médico e líder político Pedro Santos e o economista Alfredo Dolabella Portela Filho. O objetivo é investigar a trajetória desses três personagens, identificando e discutindo as suas visões e propostas para o desenvolvimento regional.
\end{abstract}

Palavras-chave: Desenvolvimento regional. Norte de Minas. Intelectuais.

Abstract: This article presents a study about ideas and practices of three intellectuals active in the North of Minas Gerais on the second half of the Twentieth Century, along with its economic modernization process: the entrepreneur Luiz de Paula Ferreira, the physician and political leader Pedro Santos and the economist Alfredo DolabellaPortella Filho. The aim of the article is to investigate the trajectory of these three men, identify and discuss their way of viewing and proposals to the development of the region.

Key-words: Regional development. North of Minas Gerais. Intellectuals.

\section{INTRODUÇÃO}

As persistentes desigualdades entre as regiões do Brasil fazem do desenvolvimento regional um tema quase permanente nos debates acadêmicos e políticos. Na segunda metade do século $X X$, essa problemática foi central, dando ensejo a iniciativas de maior envergadura, como a criação da Superintendência do Desenvolvimento do Nordeste-SUDENE, em 1959, no auge do desenvolvimentismo.

Neste artigo, recortamos a discussão para um caso específico, o norte de Minas Gerais, procurando apreender como três dos intelectuais atuantes na região enfrentaram essa temática, seja em suas ações, seja em suas formulações.

Este texto é parte de uma pesquisa maior que desenvolvemos sobre a atuação dos intelectuais norte-mineiros no processo de modernização regional, na 
segunda metade do século $\mathrm{XX} .{ }^{1}$ Aqui, concentramo-nos em três casos específicos: o empresário Luiz de Paula Ferreira, o médico e líder político Pedro Santos e o economista Alfredo Dolabella Portela Filho. Embora um deles seja professor de economia, nenhum dos nossos personagens apresenta uma discussão teórica sobre desenvolvimento regional. Não são suas ideias econômicas stricto sensu que analisaremos. Eles não são teóricos do desenvolvimento. São líderes que atuaram na academia, sociedade civil e política regional. A análise aqui se concentra precisamente nesse ponto: como eles, como líderes, expressaram caminhos para o desenvolvimento regional.

Estamos diante de personagens bastante distintos. Não obstante, é possível interrogar-se sobre a atuação deles de forma articulada. Em primeiro lugar, a temática proposta: de diferentes formas, eles apresentam e/ou representam um "modelo" de ação, uma via para o desenvolvimento norte-mineiro. Em segundo lugar, ao realizarmos a pesquisa, flagramos sua atuação comum como intelectuais, na acepção gramsciana do termo.

O estudo dos intelectuais retomou seu vigor a partir dos anos 1970, no bojo da renovação geral pela qual passou a historiografia naquela conjuntura, particularmente, a história política. Entre os trabalhos sobre o tema, destacam-se aqueles assinados por Jean-François Sirinelli. É possível que a maior contribuição dessa abordagem "francesa" esteja no destaque conferido às chamadas redes de sociabilidade e seu peso na formação e atuação dos intelectuais (SIRINELLI, 2003).

Outra referência importante nesse debate é Karl Mannheim (MANNHEIM, 1968), cujas ideias fizeram adeptos renomados no Brasil, como o bem exemplifica Celso Furtado (FURTADO, 1997). A proposição de Mannheim, de que os intelectuais constituiriam uma classe específica é, possivelmente, o ponto mais controverso da sua visão, e o elemento que se mostrou menos operacional em nossa pesquisa.

Os postulados gramscianos nos permitiram dialogar com os "franceses", particularmente, no que concerne a reconhecer que os intelectuais são pessoas integrais, cujas ações não constituem produto único da razão. A margem de autonomia dos intelectuais, explicitada pelo pensador italiano, também nos levou a tentar estabelecer pontes com as ideias de Mannheim, até o limite em que os dois autores se separam, isto é, na relação dos intelectuais com as classes.

Para Gramsci, os intelectuais são os agentes organizadores do consenso social. Eles operam, especialmente, no âmbito da sociedade civil, conferindo expressão social, cultural e política às classes sociais. Logo, nenhuma classe pode prescindir deles. Sua função é não imediatamente produtiva e é precisamente por isso que eles dispõem de uma margem de autonomia. É essa liberdade relativa de ação que lhes permite formular e articular o consenso social, atuar nas lutas de hegemonia, o que, em termos gramscianos, exige colocar questões que estão além dos interesses econômico-corporativos que, via de regra, presidem o pensamento e a ação de quem está situado no mundo imediato da produção (GRAMSCI, 2004).

Embora construídas a partir da experiência italiana, as reflexões de Gramsci revelam-se de alto valor heurístico, permitindo pensar, sem dogmatismos,

\footnotetext{
${ }^{1}$ Este artigo apresenta resultados parciais da pesquisa "Identidade regional e hegemonia de classe no norte de Minas: o papel dos intelectuais", financiada pela FAPEMIG.
} 
realidades históricas distintas, como o norte de Minas Gerais, na segunda metade do século XX.

A partir desse aporte teórico-metodológico, nossa pesquisa investiga a trajetória e pensamento de várias lideranças norte-mineiras no interior de um processo maior, que foi a modernização dessa região na chamada "Era SUDENE".

Entre esses personagens, destacamos aqui: Luiz de Paula Ferreira, Pedro Santos e Alfredo Dolabella Portela Filho. São pessoas com biografias bem distintas e, talvez precisamente por isso, são representativas de propostas distintas para o desenvolvimento regional.

\section{LUIZ DE PAULA FERREIRA: "THE SELF MADEMAN"}

Luiz de Paula Ferreira (2006, p. 72) dirigiu-se, a cavalo, até a casa de Sr. Constantino, em missão lhe atribuída pelo pai. Encontrou naquela casa precária uma negra solitária que alimentava porcos magros. A cena comoveu o menino de 10 anos de idade: "Coitada! Que triste a vida dela. Pobre e analfabeta, a viver naquele lugar ermo, a derrubar cocos para porcos, sem a menor noção civilizada do mundo".

Naquele tempo, fins da década de 1920, informa o autor (2006, p. 72), eu "andava descalço e era pobre quase tanto quanto ela". Mas, "mal me dei conta do que se passou no trajeto de volta. Tinha a cabeça ocupada em consertar o mundo...".

Esse episódio está registrado no saboroso livro de memórias e "causos", de Luiz de Paula Ferreira, onde encontramos, às vezes de forma explícita, ora de forma discreta, dados biográficos e sua visão sobre temas atinentes aos objetivos deste artigo.

No caso em questão, encontram-se algumas das imagens mais reclamadas e difundidas sobre nosso personagem. Ele é o "self madman": o menino pobre de pés descalços, de Várzea da Palma, que se tornou um grande empresário do ramo têxtil, em Montes Claros (Grupo Coteminas), Presidente do Rotary Club (1954), fazendeiro, Vice-Prefeito de Montes Claros-MG (1962-1965) e Deputado Federal pela ARENA (1967-1971).

"Luiz de Paula Ferreira é um milagre", diz o escritor Wanderlino Arruda, na primeira linha do prefácio do livro de Ferreira. Pode-se acusar Arruda de qualquer coisa, menos de incoerência: para que o filho de Várzea da Palma chegasse sozinho onde chegou, somente por uma ação sobrenatural.

No entanto, no mesmo texto em que diz que sua condição financeira era semelhante à da mulher de quem tivera pena, Ferreira também diz que seu pai fora tropeiro, comerciante e tinha uma fazenda e um sítio. Na sua casa viviam, além de sua família, "cozinheira, lavadeira e agregadas". Em seu passeio infantil a Pirapora, ele usava botinas (FERREIRA, 2006, p. 60, 68, 71, 85, 90).

Embora concordemos com Gramsci de que as experiências da vida pessoal pregressa pesam na visão de mundo dos intelectuais e que estes dificilmente se emancipam por completo dessa bagagem (GRAMSCI, 1987), não será possível detalhar a biografia de Luiz de Paula Ferreira neste artigo. Vamos nos concentrar no seu pensamento sobre questões econômicas. Em outras palavras, vamos tentar responder a uma pergunta: como o homem adulto pretendeu "consertar o mundo", como sonhou o menino? 
A segunda metade do século $X X$ reservou transformações expressivas sobre a estrutura social e econômica do norte de Minas Gerais. Um conjunto de ações levadas a efeito pelo Estado brasileiro, via SUDENE e Governo de Minas Gerais, pelos grupos dirigentes regionais, compostos, em sua maioria, por comerciantes, proprietários rurais e industriais resultou no processo de modernização econômica materializado na industrialização nos principais centros urbanos e na transformação do campo, por meio da passagem das antigas fazendas para empresas rurais, do avanço do reflorestamento e da implantação de grandes projetos de irrigação. Os custos sociais desse processo foram elevados, como revelam trabalhos diversos (BRAGA, 1985; OLIVEIRA, 2000; PEREIRA, 2007).

Luiz de Paula Ferreira participou ativamente dessa história. Radicado em Montes Claros desde a juventude, tornou-se, progressivamente, uma figura de proa na vida social do Município, como indica sua festejada eleição para a presidência do Rotary Clube de Montes Claros, em 1954 (GAZETA DO NORTE,14.01.1954, p.1), sua função de diretor da Associação Comercial e Industrial de Montes Claros, entre 1957 e 1962 (DAVID, 2003) e a criação da Fundação Educacional Luiz de Paula - FELP, em 1961, entidade mantenedora da Faculdade de Filosofia e Letras - FAFIL, primeira instituição de ensino superior na região que, posteriormente, se integraria à Fundação Universidade Norte Mineira FUNM, que se transformaria em Universidade Estadual de Montes ClarosUnimontes, em 1990 (MAIA; CORDEIRO, 2002, p. 55-56). Em 1962, ele foi eleito Vice-Prefeito de Montes Claros, cidade-polo do norte de Minas. Entre 1967 e 1971, foi Deputado Federal pela ARENA.

Conjugada a essas atividades sociais e políticas, Luiz de Paula Ferreira foi uma figura de destaque na área econômica. A separação que fazemos aqui é apenas didática. A rigor, essas atividades múltiplas se complementam. De forma significativa, nosso personagem é um dos principais acionistas da primeira indústria implantada em Montes Claros com os incentivos da SUDENE e investimentos do Banco de Desenvolvimento de Minas Gerais - BDMG, o Frigonorte, frigorífico que iniciou suas atividades em 1965, apontado por muitos como o marco inicial da "Era SUDENE" para a região.

Além de ser beneficiário direto do aporte de recursos públicos, Luiz de Paula Ferreira atuava para divulgar os incentivos, atrair investidores privados de outras regiões e intermediar a relação capital privado e poder público, como revela a história da primeira indústria, em Várzea da Palma-MG: dois empresários oriundos de Belo Horizonte, amigos de Ferreira, são instruídos por ele a instalarem uma fábrica de azulejos na cidade. Além dos incentivos da SUDENE, os empresários obtiveram isenção de impostos municipais e doação de terreno pela prefeitura local, medidas "sugeridas" pelo mesmo Ferreira (2006, p. 28), quando apresentou os investidores ao chefe do executivo daquela cidade.

A parceria econômica mais exitosa de Ferreira foi feita com outro "estrangeiro": José Alencar Gomes da Silva. Este procurava investir na área da SUDENE, com vistas ao aproveitamento dos incentivos fiscais. Daí surgiu a sociedade com Luiz de Paula Ferreira para a instalação da Companhia de Tecidos Norte de Minas - Coteminas, em 1967, empresa que se tornaria uma das maiores no ramo têxtil do país pelas décadas seguintes (UAI, 2009).

Não por acaso, Luiz de Paula Ferreira (1975, p. 10) considera a SUDENE o grande divisor de águas da história do norte de Minas, atribuindo a ela, ao 
Governo do Estado de Minas Gerais e à infraestrutura de energia e transportes o papel de grandes fatores para o "vigoroso salto para o futuro" de Montes Claros e região. Esse livro de 1975 é uma celebração dos 25 anos da Associação Comercial Industrial- $\mathrm{ACl}$ e do modelo de desenvolvimento então em curso. Este era visto, pelo autor, como um modelo benéfico para todos. Na sua visão, a cidade estaria vivendo "uma admirável união de esforços e de interesses, de todos, em favor do desenvolvimento, como meio para o incremento do bem-estar geral" (FERREIRA, 1975, p. 20).

Concretamente, como se dava a ação da SUDENE e do Governo do Estado? Por que e como a infraestrutura era tão importante? Ao responder a essas questões, pretendemos avançar no entendimento do pensamento de Ferreira e, no mesmo percurso, colocar em xeque a tese de que o tal modelo promovia o "bemestar geral".

Os incentivos fiscais foram a coluna vertebral da modernização econômica da região. As três instâncias do Estado fizeram concessões generosas ao capital privado, com vistas a atraí-lo para o norte de Minas. O caso mais expressivo é o da SUDENE. Esta que nascera como um audacioso projeto de desenvolvimento econômico e social, dentro de uma conjuntura de forte mobilização política no país, teve seu alcance restringido a partir de 1964, limitando-se, praticamente, à concessão de incentivos fiscais (TAVARES, 2000; SACHS, 2000). Foi, precisamente, a partir de 1965 que o norte de Minas passou a receber projetos financiados pela Superintendência (PEREIRA, 2007).

As isenções fiscais, via SUDENE, explica Francisco de Oliveira, subsidiavam o capital, diminuindo seu custo (OLIVEIRA, 1989). O mecanismo funciona como um garantidor ou amplificador da taxa de lucro, uma vez que reduz uma das mais altas despesas do investidor privado, que é o pagamento de impostos. O resultado dessa operação é que o Estado é privado de recursos que poderiam ser convertidos em serviços públicos. Em outros termos, os incentivos fiscais permitem a permanência ou aumento da concentração de renda no que diz respeito à divisão entre as classes, embora possa funcionar, secundariamente, como mecanismo redistributivo entre regiões. Nessa linha de raciocínio, os desequilíbrios regionais são utilizados como justificativa para a implementação de estratégias que, ao final do processo, beneficiam os donos do capital, localizados em diferentes territórios.

A infraestrutura a que se refere Ferreira é a construção da Usina de Três Marias (1961) e a ligação de Montes Claros à sua rede de transmissão (1965), a construção do Distrito Industrial de Montes Claros pelo Governo de Minas Gerais (segunda metade da década de 1960) e o asfaltamento da BR 135, que liga Montes Claros a Belo Horizonte (1972). Essas medidas, especialmente o asfaltamento e a energia elétrica, eram demandas antigas das lideranças regionais, sendo reclamadas como condições para o desenvolvimento da região (PEREIRA, 2007).

O elemento comum em todas essas obras é a presença decisiva do Estado. Três Marias foi construída pela Companhia Energética de Minas Gerais-CEMIG, a linha de transmissão para Montes Claros foi viabilizada com recursos da SUDENE, o erário mineiro pagou o distrito industrial e os recursos federais pagaram a pavimentação asfáltica Montes Claros-BH.

Dessa forma, a industrialização se fez com o decisivo apoio do Estado na viabilização do sistema viário e energético, tal como ocorreu em âmbito nacional. 
Pragmáticos, os empresários reclamam a mão do Estado nos setores que não lhes convém. É a dinâmica histórica do capitalismo, explica Harvey: O Estado assume as áreas menos interessantes ao capital privado, setores em que o lucro é incerto, requer longo prazo ou apresenta uma taxa muito reduzida (HARVEY, 2005), como eram os investimentos em energia e transportes naquela conjuntura.

Embora seja inequívoco o papel central desempenhado pelo poder público em todo o processo em análise, Luiz de Paula Ferreira aponta outros elementos tão ou mais importantes para o seu êxito pessoal e para o desenvolvimento coletivo.

Em depoimentos e escritos posteriores, ele refere-se a sua história e a de suas empresas como resultado de ações individuais. Em 1979, ao ser premiado pela Federação das Indústrias de Minas Gerais-FIEMG como o industrial do ano afirmou: "A Coteminas não resultou de um esforço isolado, mas sim do trabalho em comum meu e do outro sócio fundador, meu companheiro de diretoria, Jose Alencar Gomes da Silva" (MONTES CLAROS EM FOCO, 1979, p. 41). Em 2010, sintetizou sua história de empresário em dois parágrafos, registrando sua carreira como engraxate-comerciário-contador-empresário. O foco é colocado sobre si mesmo, "trabalhando muito e economizando" e "desafiando os pessimistas". Termina a síntese da sua historia dizendo em tom vitorioso: "Hoje estão aí 10 fábricas, sete aqui e três em Pirapora. Algumas delas com a mais moderna tecnologia existente no mundo" (FERREIRA, 2010, p. 103).

O autor trata seu êxito como um êxito coletivo, da cidade. No parágrafo seguinte ele acrescenta:

Continuo acreditando, como sempre acreditei, no futuro de Montes Claros. Não só pela sua condição de polo natural da região, mas principalmente porque o montesclarense é trabalhador, inteligente e criativo (FERREIRA, 2010, p. 103).

O discurso liberal, centrado no individuo, transparece nas palavras de Ferreira. Decisões, atitudes e esforço individual mudam a história. No seu próprio caso, instrui Ferreira, sua vida teve um giro de 180 graus quando decidiu ouvir o conselho do seu patrão, quando ainda trabalhava como comerciário: "trate com atenção os nossos fregueses" (FERREIRA, 2006, p. 121-122).

Operando em um contexto desenvolvimentista (BIELCHOWSKY, 1996), Luiz de Paula Ferreira se serve dos investimentos e incentivos estatais. Seus empreendimentos avançam sob as bênçãos do Estado. Mas, no seu discurso, não é o poder público que promove o desenvolvimento. Ao Estado cabe criar condições e facilidades para o capital privado que, ao ser bem-sucedido, possibilita o "bemestar geral." As melhorias sociais e coletivas seriam, pois, subproduto das ações individuais. Não por acaso, suas memórias enfatizam tanto pequenos episódios e experiências pessoais, aos quais ele atribui o poder de fazer giros completos em sua trajetória.

A pergunta que resta é se este pensamento e modelo podem consertar o mundo, como sonhou o menino na distante década de 1920, quando ainda morava em Várzea da Palma.

Pedro Santos: Reformismo e Desenvolvimento 
Em 1962, a Gazeta do Norte noticia como algo surpreendente o resultado da eleição para Prefeito de Montes Claros/MG (GAZETA DO NORTE,11.11.1962). De fato, a vitória de Pedro Santos, suplantando uma aliança política composta por grupos tradicionalmente hegemônicos no plano político-econômico municipal, representada pela candidatura de Enéas Mineiro, não pode ser considerada um resultado óbvio. Chama-nos atenção, ainda, o apelo de Pedro Santos às classes populares e seu recurso a elementos concernentes a ideologias reformistas em ascensão no quadro político nacional no período pré-1964. Esses dois elementos conferiram um tom particular à sua campanha, destoando-a dos padrões políticos locais. É nosso intuito, pois, perscrutar a noção de desenvolvimento regional inerente a esse inusitado personagem.

Detalhar a biografia dos indivíduos aqui estudados, como já esclarecemos, não é nosso objetivo. Interessa-nos discernir seus projetos ou perspectivas para o desenvolvimento local e regional. Mas, conhecer um pouco a respeito de suas trajetórias é imprescindível para compreendermos bem suas ideias e comportamentos.

Pedro Santos é natural de São João da Ponte/MG. Jorge de Souza Santos, seu pai, possuía fazendas na região. Nosso personagem nasceu em 1911, em uma dessas propriedades. Sua mãe chamava-se Julieta Pereira dos Santos. Ele cursou o ensino primário em Montes Claros. O ginasial e o secundário no Colégio Grambery, em Juiz de Fora, onde se destacou como desportista, conquistando um título Sul-Americano de atletismo. Formou-se pela Faculdade Fluminense de Medicina, no Rio de Janeiro, em $1938^{2}$. Na capital federal, atuou no Serviço de Assistência Médica Domiciliar e de Urgência-SAMDU e no Instituto de Aposentadorias e Pensões dos Comerciários-IAPC. Entretanto, retornou para o norte de Minas Gerais, projetando-se na medicina e na política regional ${ }^{3}$.

O pertencimento a uma família proprietária de terras e a diplomação pela Faculdade Fluminense de Medicina não deixam dúvidas sobre o vínculo de Pedro Santos com as classes superiores locais. Entretanto, sua trajetória profissional e política apresentam elementos não tradicionais que o aproximaram das classes populares. Por isso, acreditamos que Pedro Santos representa um contraponto aos outros dois personagens examinados neste artigo.

Nos diversos relatos biográficos disponíveis a respeito de Pedro Santos há um consenso. Como médico, ele foi, antes de tudo, benemérito, caridoso e humano. Essa imagem pública do nosso personagem é evocada, por exemplo, por Celso Homero Santos Oliveira (JORNAL OFICIAL DO CONSELHO REGIONAL DE MEDICINA, 2005). Ao relembrar aspectos da biografia do tio, ele ressaltou que, apesar da "promissora carreira na capital fluminense", para Pedro Santos, "a saudade sertaneja foi maior". Por esse motivo, "transferiu-se para Montes Claros, (...) onde exerceu a medicina de uma forma completa, digna e desinteressada", jamais relutando "em assistir a quem necessitava de atendimentos médicos".

\footnotetext{
${ }^{2}$ Há registros que datam sua formatura, em 1939. Durante sua graduação, continuou dedicando-se aos esportes. Foi campeão juvenil de futebol e atletismo pelo Fluminense e fez parte do time profissional do Botafogo. Representando o Brasil, conquistou o vice-campeonato mundial de atletismo.

3 Os dados biográficos de Pedro Santos mencionados neste trabalho foram obtidos em: GUIMARÃES, 1997; VIANNA, 1964; JORNAL OFICIAL DO CONSELHO REGIONAL DE MEDICINA, 2005.
} 
Ainda de acordo com Celso Homero Santos Oliveira, Pedro Santos:

(...) atendia indistintamente todas as classes sociais, ajudando aos humildes até com recursos financeiros para adquirir medicamentos. Em troca, a comunidade [o] legou um inigualável prestígio e reconhecimento, em todo o norte de Minas até o sul da Bahia. Foi Vereador, Vice-Prefeito e Prefeito de Montes Claros, em duas gestões, voltadas para o crescimento regional e assistencial (JORNAL OFICIAL DO CONSELHO REGIONAL DE MEDICINA, 2005).

Nesse testemunho, fica claro que Pedro Santos não se furtava ao tradicional clientelismo político local como estratégia de conquista do apoio popular e, por conseguinte, do poder ${ }^{4}$. Também podemos notar que seu estilo de fazer política lhe rendeu um currículo extenso na administração municipal. Todavia, importa-nos salientar aqui o que ele trouxe de novo para este cenário político paternalista, clientelista e conservador. Para isso, trazemos para análise elementos discursivos enunciados pelo próprio Pedro Santos ao longo de sua trajetória política no pré-1964, bem como conceitos sobre ele elaborados em tal contexto.

Parece-nos interessante aprofundar nossa análise em relação à sua atuação como candidato vitorioso ao cargo de Vice-Prefeito nas eleições municipais de 1959, e nas já mencionadas eleições de 1962, quando Pedro Santos conquistou seu primeiro mandato de Prefeito de Montes Claros ${ }^{5}$.

O contexto em foco definiu-se como palco de crescimento dos movimentos sociais e embates políticos no plano nacional. $E$, em âmbito municipal, percebemos claramente as ressonâncias dessa efervescência, contra a qual se ergueu o golpe civil-militar de 1964 (CARDOSO JúNIOR, 2008).

Pedro Santos surgiu na política montesclarense através da União Democrática Nacional-UDN. Por essa legenda, exerceu mandato de Vereador de 1947 a 1950. Reeleito em 3 de outubro deste ano, pelo Partido Trabalhista Nacional-PTN, permaneceu na função até 1954. Após curta ausência dos quadros políticos locais, em 1958, alçou o cargo de Vice-Prefeito, desta vez, representando o Partido Trabalhista Brasileiro-PTB, o único cargo então obtido pela agremiação (GAZETA DO NORTE. 29.01.1959). No ano seguinte, segundo informou a Gazeta do Norte, o "estimado clínico Dr. Pedro Santos" ascendeu ao diretório estadual da legenda trabalhista (GAZETA DO NORTE. 05.02.1959).

Em 1959, Pedro Santos dirigiu-se ao "povo" afirmando que, como "Vice-Prefeito pelo Partido Trabalhista Brasileiro" estaria, "como sempre", "ao lado dos pequenos e dos menos favorecidos pela sorte procurando sempre amenizar os seus sofrimentos". E ratificou: "prestigiarei as classes trabalhadoras que são os verdadeiros construtores da nação procurando elevar o nível de vida dentro da ordem e do direito" (GAZETA DO NORTE. 05.02.1959). A referência à legenda partidária - atitude demasiado atípica, face ao característico personalismo político norte-mineiro - e a interlocução com os trabalhadores, admoestando-lhes a se mobilizarem por uma representação política condizente com seus interesses

\footnotetext{
${ }^{4}$ Há diversos exemplos de médicos que ascenderam politicamente na região, através do exercício da medicina em favor dos mais necessitados. Ver PORTO, 2002 e PEREIRA, 2002.

${ }^{5}$ Pedro Santos foi Prefeito da cidade, entre 1963-1967 e 1971-1972 (GUIMARÃES, 1997).
} 
ou direitos, em detrimento das lideranças "conservadoras", enunciam o ingresso da cultura política trabalhista ou do recurso a esta no campo político local ${ }^{6}$.

$\mathrm{Na}$ campanha eleitoral de 1962, para Prefeito, candidataram-se Enéas Mineiro (UDN), João Valle Maurício (PR) e Pedro Santos (PTB). Luiz de Paula Ferreira e Mário Ribeiro disputaram o posto de Vice-Prefeito, o primeiro aliado ao candidato udenista, o último ao candidato do $\mathrm{PR}^{7}$. A disputa pela chefia do executivo municipal polarizou-se entre Enéas Mineiro, candidato da "Coligação da Vitória", "acordo político" que uniu o Parido Social Democrático/PSD, a UDN e fração majoritária do PTB $^{8}$ e Pedro Santos, candidato da "Aliança Renovadora", composta pelo Partido Libertador-PL, Movimento Trabalhista Renovador-MTR, Partido Social Progressista/PSP e Partido da Representação Popular-PRP9 .

Em situação partidária ainda indefinida, Pedro Santos (GAZETA DO NORTE, 14.01.1962) declarou "ao Povo de Montes Claros, distritos e povoados", que sua candidatura permaneceria "inarredável" e não recuaria "um passo". O motivo, afirmou ele: "tenho compromisso com o povo e si eleito, governarei para o povo", uma vez que, "sempre estive, e agora mais do que nunca, estou firme ao lado do povo". Dizia-se (GAZETA DO NORTE, 21.01.1962), ainda, consciente "das dificuldades" que o aguardavam, não tendo "recursos financeiros (...) para enfrentar os poderosos". Mas confiava em um resultado positivo, "porque os milhões nunca comprarão a consciência desta honesta gente". Dessa maneira, contando "que cada um seja um pequeno cabo eleitoral", convidava os eleitores a "derrubar de vez, esta política nefasta, de acordo, de conchavos e combinações, que tantos males têm causado e prejudicado a nosso cidadão e a nossa região".

Logo Pedro Santos seria definindo como "candidato populista" e reconhecido como "o candidato que maior profundidade vem tendo, junto as massas populares, principalmente nos bairros da cidade". A certa altura, afirmavase que "o líder populista se não for se desgastando até o dia do pleito, continuará sendo uma permanente ameaça aos seus contendores do P.S.D. e P.R." (GAZETA DO NORTE, 07.06.1962 e 02.09.1962).

O trabalhismo, o nacionalismo e temas afins projetaram-se diretamente na política montesclarense nas eleições de 1962. Cotejando anúncios pertinentes a Pedro Santos e outros informativos sobre sua campanha, disponíveis na Gazeta do

\footnotetext{
${ }^{6}$ Usamos o conceito cultura política dentro da linha de Serge Berstein (BERSTEIN. In: RIOUX; SIRINELLI, 1998, p. 350-351).

${ }^{7}$ O petebista, haja vista o fato de não ter sido apoiado por nenhum dos concorrentes a VicePrefeito, não se declarou a favor de nenhum deles em campanha, exercendo seu mandato ao lado de Luiz de Paula, que superou seu opositor nas urnas. (GAZETA DO NORTE, 02.10.1962 e 21.10.1962).

${ }^{8}$ Ao apoiar o "acordo", o PTB, então presidido pelo Coronel Domingos Lopes, sofreu uma fratura em suas fileiras, tendo a fração majoritária se posicionado a favor da aliança conservadora. Desentendendo-se com a orientação da diretoria local, Pedro Santos estudou candidatar-se por legendas inexpressivas, até que, enfim, ao que parece, obteve apoio do diretório estadual, de que fazia parte, para registrar sua candidatura pelo partido. (GAZETA DO NORTE, 7 de junho de 1962).

${ }^{9}$ As candidaturas de João Valle Maurício e Mário Ribeiro, que configuraram outra parceria para Prefeito e Vice-Prefeito, parecem ter apostado no não envolvimento direto na guerra eleitoral, o que Ihes resultou números apreciáveis, embora não suficientes para a vitória. Pedro Santos venceu para Prefeito com 5220 votos, seguido por Enéas Mineiro, que, com 4082 sufrágios, superou João Valle Maurício por apenas 18. Entre os candidatos a Vice-Prefeito o resultado foi: Luiz de Paula, eleito com 7071; Mario Ribeiro, derrotado com 5067 votos. (GAZETA DO NORTE, 21.10.1962).
} 
Norte, às diretrizes político-ideológicas atribuídas às lideranças populares, constatamos convergências no plano da cultura política que podem nos ajudar a compreender a escolha de sua candidatura por parte das camadas socioeconômicas inferiores. Ele não só se propunha a representá-las no poder. Seus materiais de campanha, discursos e comportamentos sugerem entre ele e seus prováveis eleitores uma identificação para além do clientelismo e paternalismo, fundamentada no universo do trabalhismo a que o candidato se identificava, se auto definindo "trabalhista" e "nacionalista"10. De resto, a favor da escolha popular por Pedro Santos, ainda pesava o fato de que ele se fazia passar por um tipo simples, familiar, amigo dos pobres e humanitário, aparentemente bem diverso dos concorrentes.

A especificidade da "interpelação" do petebista aos "menos favorecidos" forjou uma representação social a seu respeito que, estabelecendo-o como elemento portador de valores e símbolos que o distinguiam enquanto potencial realizador de demandas e interesses historicamente forjados ou partilhados nas experiências das classes populares, certamente, favoreceu-o nas eleições de $1962^{11}$. A interação entre populares, representantes de classe e o candidato, por meio dos eventos de campanha, serviria à multidão de eleitores no mesmo sentido. No comício de lançamento da candidatura de Pedro Santos, em princípios de julho, Robson Crusoé Lourdes de Macedo Moura, Vereador pelo PR, proferiu "um discurso altamente socialista, referindo-se a reformas de bases", combatendo "a atual administração e o governo do Estado". Patrus de Souza, líder da bancada petebista na assembleia estadual, "atacou o capitalismo" em vários aspectos, concluindo que "o povo é quem paga o pato, o tubarão é quem ganha". Pedro Santos, por fim, respondeu a críticas de adversários afirmando: "Dizem que sou desorganizado, porque atendo o pobre e o rico com a mesma consideração" (GAZETA DO NORTE, 12.07.1962).

Diante desse panorama, Pedro Santos emerge como sujeito de um projeto de desenvolvimento local algo distinto das perspectivas empreendedoras delineadas pelos demais personagens estudados neste trabalho. Se levamos a sério as conexões entre ele e o trabalhismo brasileiro (GOMES, 1994), temos no plano municipal uma versão "sertaneja" do reformismo elevado aos cimos da política nacional por João Goulart e seu grupo. Essa corrente, herdeira das ideias políticas de Getúlio Vargas, encarou o desafio de efetivar, por vias democráticas, reformas sociais (política, urbana, agrária, educacional) profundas para os padrões do atávico conservadorismo brasileiro. Tanto que dispôs seus adversários a uma solução traumática para contê-la: o golpe civil-militar de 1964.

Portanto, a trajetória social, educacional e profissional de Pedro Santos não escapa aos modelos das classes hegemônicas. Por sinal, ele se comprometeu com causas importantes para estes segmentos, como inserção do norte de Minas

\footnotetext{
10 Dessa maneira, contemplava expectativas comprovadamente defendidas no âmbito das "associações de classe", em tese e ao que tudo indica também na prática, termômetro das inclinações políticas dos trabalhadores em geral no contexto examinado. Zeferino Oliveira Guedes, que foi membro de diversas associações de trabalhadores locais, deixando-nos uma evidência da orientação política destes, definiu-se a si mesmo e ao extrato social de que fazia parte, como "nós os eleitores independentes, que somos contra os trustes, os entreguistas, os Calabás e os Silvérios dos Rêis". (GAZETA DO NORTE, 16.09.1962).

${ }^{11}$ Empregamos o termo "interpelação" conforme definido por FERREIRA, 2001, p. 101-103.
} 
na área de atuação da SUDENE, a implantação do distrito industrial de Montes Claros, etc. (JORNAL OFICIAL DO CONSELHO REGIONAL DE MEDICINA, 2005). Todavia, desviou-se do cânon conservador ao assumir um projeto político que acenava para um desenvolvimento econômico-social mais favorável à integração dos setores populares à riqueza capitalista, o trabalhismo.

\section{Alfredo Dolabella: "Sem separação não há solução": O desenvolvimento através do separatismo}

Enquanto Luiz de Paula Ferreira se serve dos incentivos e subsídios estatais para levar adiante seus empreendimentos privados e exalta os valores individuais para se obter o desenvolvimento, Pedro Santos se filia a um projeto distributivista, nacionalista, reformista; Alfredo Dolabela concentra suas energias em um projeto inteiramente específico e abertamente regionalista.

Ele dedicou parte da sua vida a um projeto que, segundo seu sonho, acabaria com os problemas sociais da região em que vivia. Alfredo Dolabella Portella Filho, ao lado de lideranças como Simeão Ribeiro e Expedicto Mendonça, liderou expressivos movimentos de cunho separatista no norte de Minas.

Não pretendemos descrever minuciosamente os movimentos emancipacionistas que ocorreram na região, na segunda metade do século $X X^{12}$, mas destacar o pensamento de Alfredo Dolabella e seu engajamento nesses movimentos.

Na segunda metade do século $X X$, ocorreram três movimentos de cunho separatista ${ }^{13}$. O primeiro deles em prol da criação do Estado de Cabrália, o segundo pela criação do Estado de São Francisco e o terceiro pelo Estado de Minas do Norte. Dolabella participou ativamente dos dois últimos movimentos, fomentou debates, contribuiu para a elaboração de projetos de Lei, liderou e organizou comissões e publicou diversos estudos sobre o tema.

Alfredo Dolabella Portella Filho nasceu no Rio de Janeiro-RJ, em 1928. Teve a sua vida intimamente ligada ao universo acadêmico, realizou diversos cursos complementares no exterior. Em 1951, depois de ter se formado em Engenharia nos Estados Unidos, aprofundou seus estudo na área das Ciências Econômicas, formando-se em Economia, em 1958, pela Universidade Federal do Rio de JaneiroUFRJ. A partir da década de 1980, ele já estava estabelecido na região do norte de Minas. Foi em Montes Claros que Dolabella se tornou professor universitário.

Durante vários anos ministrou aulas na FUNM que, posteriormente, transformou-se na Unimontes. No âmbito acadêmico, Dolabella atuou também como agente organizador, fundou instituições, associações de professores, chefiou departamentos e cooperativas. Em um dos seus livros ele destaca o fato de ter sido eleito, sucessivamente por nove anos, diretor da Faculdade de Administração e Finanças - FADEC, integrada no grupo de faculdades que vieram a constituir a FUNM ${ }^{14}$.

Desde o início da pesquisa, uma pergunta nos inquietava: por que esse intelectual, oriundo do Rio de Janeiro, teve a sua vida profissional e política tão

\footnotetext{
12 Para saber mais sobre o tema ler: PEREIRA, 2007.

13 Ibid.p. 85-145.

${ }^{14}$ Dados biográficos extraídos do livro: PORTELLA FILHO, 2009.
} 
ligada ao norte de Minas? Para respondermos essa pergunta é preciso recorrer à história de outro homem, o seu pai, Alfredo Dolabella Portella. Este, além de possuir um extenso currículo universitário, era dono de grandes extensões territoriais. Neto de Fazendeiro e filho de professores, Dolabella trabalhou diversos anos em obras ferroviárias. Utilizando sua experiência na área, em 1910, em associação com seu tio - o engenheiro Ludgero Dolabella - criou a empresa Cia. Dolabella \& Portella Ltda.

A principal fonte de renda de Dolabella, o pai, foram as possessões de terras. Segundo seu filho, ele "ganhou muito dinheiro adquirindo as terras por onde a estrada de ferro deveria ser construída e revendendo-as, posteriormente, por um preço elevado ao Governo" 15 . Ainda nas primeiras décadas do século XX, Dolabella decidiu adquirir terras no Norte de Minas, mais precisamente no Município de Bocaiúva.

A influência de Dolabella foi tão grande na região, que hoje há um Distrito de Bocaiúva que carrega o seu nome, Engenheiro Dolabella (distrito localizado a $45 \mathrm{~km}$ da sede do Município de Bocaiúva).

Segundo os estudos de Pereira, o pai do nosso personagem adquiriu:

(...) entre 1910 e 1930, 33 mil alqueires de terra na microrregião de Bocaiúva. Nessas terras, Alfredo Dolabela, o pai, organizou uma grande plantação de cana e produção. Em 1944, a Cia. Agroindustrial Dolabela Portella foi vendida para as Indústrias Reunidas Francisco Matarazzo (PEREIRA, 2007, p. 111).

Segundo Dolabella Filho, seu pai investiu na região de Bocaiúva, principalmente, em virtude de dois fatores. O primeiro deles, como já fora ressaltado anteriormente, é a construção de uma estrada de ferro de Belo Horizonte a Bocaiúva. O outro motivo é explicado por Pereira nos seguintes termos:

segundo Alfredo Dolabela, o filho, seu pai era amigo e companheiro político de Fernando Mello Viana, Governador de Minas Gerais, em 1925 e Vice-Presidente da República, entre 1926-1930, e teria, entre suas propostas, o projeto de criação de um novo Estado na região, cuja capital seria construída exatamente na microrregião em que Dolabela adquiriu os 33 mil alqueires de terra. Concretizando o projeto, os lucros do empresário seriam fabulosos (PEREIRA, 2007, p. 111).

Como sabemos, tal projeto não se concretizou. Dolabella Filho utilizou desses argumentos para justificar historicamente a causa separatista que tanto defendia. Embora não citemos todos neste texto, tivemos acesso a diversos artigos publicados pelo nosso personagem, nos jornais de circulação local, entre os anos de 1985 e 2005. Em seus textos, fica bastante clara uma linha de raciocínio, uma ideia que lhe servia para justificar tal causa, isto é, o desenvolvimento é o resultado da emancipação.

Em um dos panfletos de divulgação da causa emancipacionista ele afirma que: "Chegou a hora de colocarmos um basta nesta condição de penúria. Hoje

\footnotetext{
${ }^{15}$ O Estado de Minas do Norte já na década 30?. Panfleto de divulgação da causa separatista (sem ano de publicação registrado). p. 03. Disponível no arquivo privado de Alfredo Dolabella, em sua residência.
} 
sabemos que existe solução e ela depende de nós: criando-se um novo Estado" (PORTELA FILHO, 2009) ${ }^{16}$.

Em outro panfleto ele afirma: "A emancipação política é a melhor solução para o rápido desenvolvimento social e econômico de nossa região. Os opositores que venham apresentar uma alternativa melhor" (PORTELA FILHO, 2003).

As considerações de Antonio Gramsci (1976), sobre a organização dos grupos sociais, nos parecem válidas a esse respeito. Segundo ele, é possível distinguir três estágios nesse processo. O primeiro deles, denominado econômicocorporativismo, é a fase em que alguns setores atuam de forma isolada, defendendo seus interesses específicos. Numa segunda etapa, os interesses se expandem e buscam o Estado como aliado, no entanto, ainda está limitado ao campo econômico.

O ultimo estágio é aquele em que o grupo social adquire um grau de coesão e, consequentemente,

(...) a consciência de que os próprios interesses corporativos, no seu desenvolvimento atual e futuro, superam o círculo corporativo, de grupo meramente econômico, e podem e devem tornar-se os interesses de outros grupos subordinados (GRAMSCl, 1976, p. 50).

A atuação de Dolabella por meio da imprensa representa os dois últimos estágios. Por diversas vezes, ele convoca as lideranças políticas ao engajamento e, mais do que isso, aborda a problemática separatista como uma causa apartidária ou suprapartidária, reunindo as classes sociais, propondo-a como um projeto de toda a sociedade, em um explícito esforço de universalizar seu projeto ${ }^{17}$.

Em relação a tal proposta, Dolabella afirma que:

é necessário ficar bem claro que é imprescindível a mobilização da opinião pública no sentido de apoiar projeto de tal envergadura. Se de um lado, o impacto será de grande benefício, de outro lado, será uma mudança radical, em todos os órgãos da União, no Executivo, no Legislativo e, inclusive, no Judiciário. Em todas as grandes transformações ocorridas no mundo ou mesmo no Brasil, a adesão da maioria da opinião pública é fator decisivo (PORTELA FILHO, 2005, p. 06).

Alfredo Dolabella encarna o intelectual de que falava Gramsci, um agente organizador, elaborador e difusor dos interesses das classes a que integrava, mas que se coloca, no discurso, fora das classes, precisamente para melhor representálas (PORTELLI, 2002). Ele acreditava de forma veemente, que a emancipação política da região do norte de Minas era a alternativa mais viável para atingir "o progresso" e, por conseguinte, debelar os problemas sociais da região.

\footnotetext{
${ }^{16}$ Povo do Norte de Minas, até quando teremos que aceitar a atual situação? - Panfleto de campanha da causa separatista. Sem data registrada na publicação. Disponível no arquivo particular de Alfredo Dolabella, localizado em sua residência.

${ }^{17}$ Podemos citar como exemplo o texto "Movimento Seremos 3" dá nova 'cara' a Minas. Montes Claros: Jornal de Notícias, 30/06/2004. E no artigo intitulado Divisão Territorial. Montes Claros:Gazeta Norte Mineira, 16/03/2005, neste texto ele comenta o apoio do então VicePresidente da República José Alencar. Ambos de autoria de PORTELLA FILHO.
} 
O professor Dolabella tentou através de diversos meios, principalmente por meio de publicações em impressos locais, manter o assunto nos debates políticos. Entretanto, o debate cessou. As divisões entre os grupos dirigentes regionais e, principalmente, a contraofensiva do governo de Minas Gerais, frustraram os sonhos emancipacionistas (PEREIRA, 2007).

O pensamento de Dolabella Filho expressa uma corrente importante na história regional, uma vez que, por quatro décadas - 1960 a 2000, a alternativa separatista alimentou os discursos e projetos de várias lideranças políticas no norte de Minas.

Embora o projeto do novo Estado não tenha logrado êxito, o discurso e as ideias produzidas em função dele contribuíram para solidificar uma ideologia regionalista, que funcionou como um dos fundamentos da hegemonia de proprietários rurais, grandes comerciantes e indústrias da região, no período de modernização econômica. O núcleo duro dessa ideologia consistia em atribuir a fatores "externos" a causa das desigualdades sociais. Nesse raciocínio, ganham relevância a Providência/natureza/clima/secas, a exploração da região pelo centrosul do Estado e a abandono do poder público.

Centrado nesses dois últimos pontos, frações importantes dos grupos dirigentes regionais, com a notável participação de Alfredo Dolabella Portela Filho, alimentaram o sonho separatista, levando água para o mesmo moinho da negação das estruturas econômicas presentes em âmbito nacional e regional, razão profunda das desigualdades.

\section{CONSIDERAÇÕES FINAIS}

Luiz de Paula Ferreira tem um estilo ponderado, aspecto particularmente expressivo na vida política e nos textos que produz. O regionalismo não é uma das suas marcas. Como um bem sucedido capitalista, compreende a livre-iniciativa como um dos aspectos centrais do desenvolvimento, atribuindo ao setor público o papel de incentivador dos empreendimentos privados. Como um bom liberal, acreditou que o desenvolvimento regional e a solução para as desigualdades econômico-sociais norte-mineiras viriam como resultado da soma das riquezas particulares. Pragmático, manteve-se distante do movimento separatista de 19671968, que pretendeu criar o Estado de Cabrália, emancipando o norte de Minas e o Sul da Bahia, e foi contrário ao movimento Estado de São Francisco, na década de 1990 (PEREIRA, 2007).

Pedro Santos revela-se um personagem dotado de comportamento político atípico no contexto estudado. Oriundo de família dotada de boas condições materiais, alcançou formação superior em medicina, tornando-se um líder político carismático, com penetração popular marcante. Sua proximidade com o povo, estabelecida por meio do exercício da medicina e da política, ainda é uma característica presente nas representações sociais a seu respeito. Além disso, como procuramos destacar, em fase importante de sua carreira política, em que exerceu mandado de Vice-Prefeito e tornou-se candidato vitorioso ao seu primeiro mandado de Prefeito, identificou-se à cultura política trabalhista brasileira. Sua trajetória ficou marcada por defender um projeto reformista e distributivista de desenvolvimento, dentro da ordem capitalista, mas centrado no princípio de redução das desigualdades que penalizam as classes trabalhadoras. 
Alfredo Dolabella mostrou-se um intelectual na acepção gramsciana por excelência. Transformou interesses econômico-políticos, familiares e corporativos em um projeto político separatista de envergadura regional, pretensamente suprapartidário. Empreendeu notáveis esforços políticos, intelectuais e discursivos em favor do suposto caráter universal do seu programa de desenvolvimento pautado na emancipação regional e agregou seguidores de expressão. Não obstante, sua ideologia escamoteava seu pragmatismo empreendedor, assim como obscurecia as razões intrínsecas das desigualdades da região, vinculadas ao elitismo do projeto de desenvolvimento conduzido pelas classes hegemônicas regionais. A estratégia empregada, nesse sentido, consistiu em atribuir a responsabilidade sobre as mazelas do norte de Minas a fatores exógenos. Conseguintemente, legitimando interesses das classes hegemônicas locais apesar da miséria da maioria.

Portanto, cada um a seu modo, Luiz de Paula Ferreira, Pedro Santos e Alfredo Dolabela atuaram como intelectuais em termos gramscianos, na história da modernização capitalista regional. Isto é, projetaram-se acima de interesses corporativos imediatistas, alegando a defesa de diferentes projetos de desenvolvimento regional, respectivamente pautados na livre-iniciativa, no reformismo distributivista e no emancipacionismo. Observando retrospectivamente tais projetos, parece-nos que triunfaram as cores da bandeira empunhada por Luiz de Paula Ferreira. Entretanto, embora não seja mais assunto para este trabalho, importa registrar a importância da estratégia de Pedro Santos para o processo de mobilização popular que marcou o cenário político montesclarense no pré-1964 (CARDOSO JÚNIOR, 2008), e as contribuições do ideal separatista de Alfredo Dolabela para a definição de uma identidade regional norte mineira (PEREIRA, 2007).

\section{REFERÊNCIAS}

BERSTEIN, Serge. A cultura política. In.: RIOUX; SIRINELLI (Orgs.). Para uma história cultural. Lisboa: Estampa, 1998. p. 349-363.

BIELSCHOWSKY, Ricardo. Pensamento econômico brasileiro: o ciclo ideológico do desenvolvimentismo. 3a . Ed. Rio de Janeiro: Contraponto, 1996.

BRAGA, Maria Angela Figueiredo. Industrialização da Área Mineira da SUDENE um estudo de caso. Dissertação (Mestrado em Economia) - Departamento de Economia, Universidade Federal da Paraíba, João Pessoa, 1985.

CARDOSO JÚNIOR, Edi de Freitas. Experiência e poder na urbe em expansão: "cultura política popular" em Montes Claros/MG, entre 1930 e 1964. 2008. 204 f. Dissertação (Mestrado em História) - Faculdade de Filosofia e Ciências Humanas, Universidade Federal de Minas Gerais, Belo Horizonte, 2008.

DAVID, Zoraide Guerra. Historiando o Progresso. Montes Claros: ACl, 2003.

FERREIRA, Jorge. O nome e a coisa: o populismo na política brasileira. In: FERREIRA, Jorge (Org.). O populismo e sua história: debate e crítica. Rio de Janeiro: Civilização Brasileira, 2001. p. 59-124. 
FERREIRA, Luiz de Paula. Aspectos do Desenvolvimento de Montes Claros. Belo Horizonte: Imprensa Oficial, 1975.

FERREIRA, Luiz de Paula. Cidade acolhedora. Revista do Instituto Histórico e Geográfico de Montes Claros. Montes Claros, 2010.

FERREIRA, Luiz de Paula. Na venda de meu pai. Montes Claros: Unimontes, 2006.

FURTADO, Celso. Celso Furtado: obra autobiográfica. Rio de Janeiro: Paz e Terra, 1997, 3 v., v. 1.

GAZETA DO NORTE. Montes Claros. Diário. 14 de janeiro de 1954.

GAZETA DO NORTE. Montes Claros. Diário. 11 de janeiro de 1959.

GAZETA DO NORTE. Montes Claros. Diário. 29 de janeiro de 1959.

GAZETA DO NORTE. Montes Claros. Diário. 05 de fevereiro de 1959.

GAZETA DO NORTE. Montes Claros. Diário. 14 de janeiro de 1962.

GAZETA DO NORTE. Montes Claros. Diário. 21 de janeiro de 1962.

GAZETA DO NORTE. Montes Claros. Diário. 07 de junho de 1962.

GAZETA DO NORTE. Montes Claros. Diário. 08 de julho de 1962.

GAZETA DO NORTE. Montes Claros. Diário. 12 de julho de 1962.

GAZETA DO NORTE. Montes Claros. Diário. 02 de setembro de 1962.

GAZETA DO NORTE. Montes Claros. Diário. 16 de setembro de 1962.

GAZETA DO NORTE. Montes Claros. Diário. 02 de outubro de 1962.

GAZETA DO NORTE. Montes Claros. Diário. 21 de outubro de 1962.

GAZETA DO NORTE. Montes Claros. Diário. 11 de novembro de 1962.

GOMES, Ângela de Castro. A invenção do trabalhismo. $2^{\mathrm{a}}$ Ed. Rio de Janeiro: Relume Dumará, 1994.

GRAMSCI, Antonio. A questão meridional. Rio de Janeiro: Paz e Terra, 1987.

GRAMSCI, Antônio. Cadernos do Cárcere - vol. 1. Edição e tradução: Carlos Nelson Coutinho; co-edição: Luiz Sérgio Henriques e Marco Aurélio Nogueira - $3^{a}$ Ed. Rio de Janeiro: Civilização Brasileira, 2004. 
GRAMSCI, Antonio. Maquiavel, a política e o Estado Moderno. Rio de Janeiro: Civilização Brasileira, 1976.

GUIMARÃES, Jorge Tadeu. As Faces do Legislativo. Montes Claros/MG: Sociedade Educacional Arapuim, 1997.

HARVEY, David. A produção capitalista do espaço. São Paulo: Annablume, 2005.

JORNAL OFICIAL DO CONSELHO REGIONAL DE MEDICINA. Dr. Pedro Santos. Ano 1. No 39. Agosto de 2005. Disponível em:<http://jornal.crmmg.org.br/ago05/07_memoria.php $>$. Acesso em: 3 de setembro de 2012.

MAIA, Claudia de Jesus; CORDEIRO, Filomena Luciene. As faculdades da FUNM. In:CALEIRO, Regina Celia Lima; PEREIRA, Laurindo Mekie (Orgs.). Unimontes: 40 anos de história. Montes Claros: Unimontes, 2002. Disponível em: $<$ www.50anos.unimontes.br/index.php/historia $>$. Acesso em: 10 de junho de 2013.

MANNHEIM, Karl. Ideologia e Utopia. Rio de Janeiro: Zahar, 1968.

MONTES CLAROS EM FOCO. Montes Claros, 1979.

OLIVEIRA, Evelina Antunes Fernandes. Nova cidade, velha política: Poder local e desenvolvimento regional na Área Mineira do Nordeste. Maceió: EDUFAL, 2000.

OLIVEIRA, Francisco de. A economia da dependência imperfeita. 5. ed. Rio de Janeiro: Graal, 1989.

PEREIRA, Laurindo Mékie. A cidade do favor. Montes Claros em meados do século XX. Montes Claros/MG: UNIMONTES, 2002.

PEREIRA, Laurindo Mékie. Em nome da região, a serviço do capital: o regionalismo político norte-mineiro. Tese (Doutorado em História), USP-FFLLCH, São Paulo, 2007.

PORTELLA FILHO, Alfredo Dolabella. O remanescente do Estado de Minas Gerais seria prejudicado com a emancipação política da região Norte? Montes Claros: Jornal de Notícias, 27/04/2003.

PORTELLA FILHO, Alfredo Dolabella. Redivisão territorial acelera o desenvolvimento. Montes Claros: O Norte de Minas, 31/12/2005.

PORTELLA FILHO, Alfredo Dolabella. Três passos para um mundo melhor. três boas ideias. Montes Claros: Unimontes, 2009.

PORTELLI, Hugues. Gramsci e o bloco histórico. 6ªd. Rio de Janeiro: Paz e Terra, 2002. 
PORTO, César Henrique de Queiroz. Paternalismo, poder privado e violência: o campo político norte-mineiro durante a Primeira República. 2002. $173 \mathrm{f}$. Dissertação (Mestrado em História - Culturas Políticas) - Faculdade de Filosofia e Ciências Humanas, Universidade Federal de Minas Gerais, Belo Horizonte, 2002.

SACHS, Ignacy; FORMIGA, Marcos (Coord.). Celso Furtado: a SUDENE e o Futuro do Nordeste. Seminário Internacional: Homenagem aos 80 anos de Celso Furtado e aos 40 anos de criação da SUDENE. Recife: SUDENE, 2000.

SIRINELLI, Jean-François. Os intelectuais. In: RÉMOND, René. (org.). Por uma história política. Rio de Janeiro: FGV, 2003.

TAVARES, Maria da Conceição (org.). Celso Furtado e o Brasil. São Paulo: Perseu Abramo, 2000.

UAl. Vocação Empreendedora de Alencar começou aos 14 anos. Disponível em: $<$ www.uai.com.br/htmls/app/noticia173/2009/07/17/noticia_interna_especial iose_alencar, $\mathrm{i}=168142 / \mathrm{VOCACAO}+$ EMPREENDEDORA+DE + ALENCAR + COMECOU+AOS+14+ANOS.shtml>. Acesso em: 10 de jun. 2013.

UNIMONTES. Unimontes 50 Anos - Histórico da Unimontes. Disponível em: $<$ www.50anos.unimontes.br/index.php/historia > . Acesso em: 3 de set. 2012.

VIANNA, Nelson. Efemérides Montesclarenses. Rio de Janeiro: Irmãos Pongetti editores, 1964.

Submetido em: 05/11/2013.

Aprovado em: 30/06/2015.

\section{Sobre ao autores}

Ilva Ruas Abreu

Doutora em Historia pela UFMG. Professora e Coordenadora do Mestrado em História da Universidade Estadual de Montes Claros - Unimontes.

Endereço: Campus Universitário Professor Darcy Ribeiro s/n, Vila Mauricéia. 39401-089 - Montes Claros, MG, Brasil.

E-mail: Ilvaruas@gmail.com

\section{Laurindo Mekie Pereira}

Doutor em História Econômica pela USP. Professor do Mestrado em História da Universidade Estadual de Montes Claros - Unimontes. Bolsista BIPDT/FAPEMIG.

Endereço: Campus Universitário Professor Darcy Ribeiro s/n, Vila Mauricéia. 39401-089 - Montes Claros, MG, Brasil.

E-mail:mekie1@hotmail.com

Edi de Freitas Cardoso Junior

Mestre em História pela UFMG. Professor do Instituto Federal do Norte de Minas Gerais/IFNMG.

Endereço: Fazenda Meio Pé da Serra, BR 367 s/n. 39600-000 - Araçuaí, MG, Brasil.

E-mail: edfcardoso@yahoo.com.br 